\title{
Evaluation of the new TNM-staging system for thymic malignancies: impact on indication and survival
}

\author{
Michael Ried ${ }^{1 *}$ D, Maria-Magdalena Eicher ${ }^{1}$, Reiner Neu ${ }^{1}$, Zsolt Sziklavari ${ }^{2}$ and Hans-Stefan Hofmann ${ }^{1,2}$
}

\begin{abstract}
Background: The objective of this study is the evaluation of the Masaoka-Koga and the International Association for the Study of Lung Cancer (IASLC)/International Thymic Malignancy Interest Group (ITMIG) proposal for the new TNM-staging system on clinical implementation and prognosis of thymic malignancies.

Methods: A retrospective study of 76 patients who underwent surgery between January 2005 and December 2015 for thymoma. Kaplan-Meier survival analysis was used to determine overall and recurrence-free survival rates.

Results: Indication for surgery was primary mediastinal tumor $(n=55)$, pleural manifestation $(n=17)$, or mediastinal recurrence $(n=4)$ after surgery for thymoma. Early Masaoka-Koga stages I $(n=9)$ and II $(n=14)$ shifted to the new stage I ( $n=23$ ). Advanced stages III (Masaoka-Koga: $n=20$; ITMIG/IASLC: $n=17$ ) and IV (Masaoka-Koga: $n=33$; ITMIG/IASLC: $n=35$ ) remained nearly similar and were associated with higher levels of WHO stages. Within each staging system, the survival curves differed significantly with the best 5-year survival in early stages I and II (91\%). Survival for stage IV (70 to $77 \%$ ) was significantly better compared to stage III (49 to 54\%). Early stages had a significant longer recurrence-free survival (86 to 90\%) than advanced stages III and IV (55 to 56\%).

Conclusions: The proportion of patients with IASLC/ITMIG stage I increased remarkably, whereas the distribution in advanced stages III and IV was nearly similar. The new TNM-staging system presents a clinically useful and applicable system, which can be used for indication, stage-adapted therapy, and prediction of prognosis for overall and recurrence-free survival.
\end{abstract}

Keywords: Thymoma, Thymic carcinoma, TNM staging, Masaoka-Koga, Staging system

\section{Background}

Main objective of therapy in all stages of thymoma and thymic carcinoma should be complete surgical resection based on a stage-adapted treatment including multimodality therapy in advanced stages [1-3]. Prognosis depends on the preoperative tumor stage mainly characterized by the anatomical extend (Masaoka-Koga classification), the World Health Organization (WHO) histological classification system, and the completeness of surgical resection [4-8]. At least 15 different stage classification systems for thymic tumors have been proposed and implemented in the last decades [9]. However, the

\footnotetext{
*Correspondence: michael.ried@ukr.de

'Department of Thoracic Surgery, University Medical Center Regensburg,

Franz-Josef-Strauß-Allee 11, 93053 Regensburg, Germany

Full list of author information is available at the end of the article
}

Masaoka-Koga classification remains the most common and frequently applied clinical staging system [10].

Recently, the International Association for the Study of Lung Cancer (IASLC) and the International Thymic Malignancy Interest Group (ITMIG) have proposed a new classification for thymic malignancies [11, 12]. The IACLC/ITMIG staging system has now been approved by the Union for the International Cancer Control (UICC) and the American Joint Committee on Cancer (AJCC) in the eight edition of the TNM classification [13, 14].

Objective of this study was the evaluation of patients with thymoma or thymic carcinoma who underwent surgical resection and to compare their characteristics, indications for surgery, and outcomes when classified according to the Masaoka-Koga system and with the new proposed IASLC/ITMIG TNM-staging system. 


\section{Methods}

\section{Study design}

This was a retrospective, non-randomized study at the Department of Thoracic Surgery, University Medical Center Regensburg, and the Department of Thoracic Surgery, Hospital Barmherzige Brüder Regensburg. Between January 2005 and December 2015, a total of 76 consecutive patients with thymoma or thymic carcinoma, who underwent radical surgical resection, were included.

The study was approved by our Institutional Review Board, which waived the requirement for an individual patient consent because only routine patient data were used for this retrospective analysis. Patient characteristics and operative reports were obtained from the institutional database and medical records. Preoperative staging included contrast-enhanced computed tomography $(\mathrm{CT})$ scan of the chest in all patients. The preoperative clinical and pathologic stage was determined according to Masaoka-Koga staging system [7]. The pathologic results were classified according to the WHO histological classification system [14, 15]. The proposed IASLC/ITMIG stages were determined, using the preoperative imaging in addition to histological, surgical, and medical reports.

Induction therapy was administered in patients with advanced tumor stages, which were considered not completely resectable and in order to increase the chance for complete resection. Adjuvant therapies including chemotherapy or radiotherapy were accomplished depending on tumor stage, histology, completeness of resection, and the postoperative patient's status [3]. A further reason for not performing adjuvant therapy was patient refusal.

During the study period, eight patients with recurrence of thymoma underwent surgical resection again without any complication and with a macroscopic complete tumor resection (mediastinal or lung: R0; pleural: R0/R1).

\section{Proposed IASCL/ITMIG staging system}

The proposed IASLC/ITMIG staging system was first published 2014 and is a new evidence-based TNM-staging system for thymic malignancies according to the TNM classification of the UICC of malignant tumors (Table 1) $[11,13,14]$. The greatest significance has the $\mathrm{T}$ descriptor, which evaluates the local tumor invasion, whereas nodal or distant metastases are uncommon [16]. It describes the invasion into mediastinal fat (T1a), mediastinal pleura (T1b), pericardium (T2), and other surrounding structures or organs (T3, T4) [17]. The $\mathrm{N}$ descriptor distinguishes between involvement of N1 (anterior/perithymic) and N2 (deep intrathoracic/cervical) lymph nodes [18]. The M descriptor indicates whether pleural and pericardial nodules (M1a) or distant organ metastases (M1b), including pulmonary intraparenchymal metastases, are evident [19].

\section{Follow-up}

Overall survival and recurrence-free survival were calculated from the date of surgery. Follow-up analysis was

Table 1 Stages of thymic tumors according to Masaoka-Koga classification and the proposed IASLC/ITMIG classification [5, 7, 13]

\begin{tabular}{|c|c|c|}
\hline Stage & Masaoka-Koga & IASCL/ITMIG \\
\hline | & $\begin{array}{l}\text { Completely encapsulated tumor } \\
\text { Invasion into but not through the capsule }\end{array}$ & $\begin{array}{l}\text { T1N0M0 } \\
\text { T1a: Encapsulated or extending into the anterior mediastinal fat } \\
\text { T1b: Direct involvement of the mediastinal pleura }\end{array}$ \\
\hline$\|$ & $\begin{array}{l}\text { (a) Microscopic transcapsular invasion } \\
\text { (b) Macroscopic invasion into thymic or surrounding fatty tissue } \\
\text { Grossly adherent to but not breaking through mediastinal pleura } \\
\text { or pericardium }\end{array}$ & $\begin{array}{l}\text { T2NOMO } \\
\text { T2: Invasion to the pericardium }\end{array}$ \\
\hline III & $\begin{array}{l}\text { Invasion into neighboring organ including } \\
\text { - Mediastinal pleura } \\
\text { - Pericardium } \\
\text { - Visceral pleura or lung } \\
\text { - Phrenic or vagus nerve } \\
\text { - Major vessels } \\
\text { Adherence of lung or adjacent organs }\end{array}$ & $\begin{array}{l}\text { (a) T3NOM0 } \\
\text { T3: Invasion to } \\
\text { - Lung } \\
\text { - Brachiocephalic vein } \\
\text { - Superior vena cava } \\
\text { - Chest wall } \\
\text { - Phrenic nerve } \\
\text { (b) T4NOM0 } \\
\text { T4: Invasion to } \\
\text { - Aorta } \\
\text { - Intrapericardial pulmonary artery } \\
\text { - Myocardium } \\
\text { - Trachea } \\
\text { - Esophagus }\end{array}$ \\
\hline IV & $\begin{array}{l}\text { (a) Pleural or pericardial metastases } \\
\text { (b) Any nodal involvement and distant metastases }\end{array}$ & $\begin{array}{l}\text { (a) TanyN1M0, TanyNOM1a } \\
\text { N1: Anterior (perithymic) nodes } \\
\text { M1a: Separate pleural or pericardial nodule } \\
\text { (b) N2 and/or M1b } \\
\text { N2: Deep intrathoracic or cervical nodes } \\
\text { M1b: Pulmonary intraparenchymal nodule or distant organ metastasis }\end{array}$ \\
\hline
\end{tabular}


conducted until either death or at the end of March 2016 in order to document tumor recurrence and the patients' overall survival.

\section{Statistical analysis}

Statistical analysis was performed with SPSS 16.0 (SPSS Inc., Chicago, IL) for Windows (Microsoft Corp, Redmond, WA). Descriptive statistics were used to describe patient characteristics and to compare variables. Categorical data are shown as frequency distributions $(n)$ and percentages (\%). The Kaplan-Meier method was used to plot survival curves, and the log-rank test was used to evaluate differences between subgroups. To perform the statistical evaluation of the two staging systems, we estimated the hazard ratio for each group in the two systems using the Cox regression analysis. Differences with a $p$ value of $<0.05$ were considered to be statistically significant.

\section{Results}

\section{Patient characteristics}

Patient characteristics are listed in Table 2. The study comprised a total of 76 patients $(53.9 \%$ male) with evidence of thymoma or thymic carcinoma, which was first

Table 2 Patient characteristics

\begin{tabular}{ll}
\hline Variable & $n=76$ \\
& $(100 \%)$ \\
\hline Gender & \\
Male & $41(53.9)$ \\
Female & $35(46.1)$ \\
Age (mean; \pm SD) [years] & $52.6( \pm 14.3)$ \\
Myasthenia gravis & $39(51.3)$ \\
Type of tumor & \\
Primary mediastinal tumor & $55(72.4)$ \\
Pleural tumor spread & $17(22.4)$ \\
Mediastinal recurrence & $4(5.2)$ \\
WHO classification & \\
A & $2(2.6)$ \\
AB & $5(6.6)$ \\
B1 & $5(6.6)$ \\
B2 & $28(36.8)$ \\
Mixed B2/B3 & $8(10.5)$ \\
B3 & $18(23.7)$ \\
C (thymus carcinoma) & $10(13.2)$ \\
Preoperative treatment & \\
None & \\
Induction chemotherapy & $43(56.6)$ \\
Ractreotid/prednisone & $28(36.8)$ \\
\hline & $5(6.6)$ \\
Radiotherapy & $0(0)$ \\
\hline
\end{tabular}

SD standard deviation, WHO World Health Organization identified as a primary mediastinal tumor ( $n=55$; 72.4\%), pleural manifestation $(n=17 ; 22.4 \%)$, or as a suspected mediastinal recurrence $(n=4 ; 5.2 \%)$ after resection of a malignant thymic tumor before the study period. Patients with advanced tumor stages (Masaoka-Koga stages III and IV) received frequently preoperative medicamentous treatment $(n=33 ; 43.4 \%)$ with induction chemotherapy $(n=28 ; 36.8 \%)$ or octreotid/prednisone $(n=5 ; 6.6 \%)$.

\section{Operative data}

Details of the surgical procedures and postoperative data are listed in Table 3. In all patients, a radical tumor resection including the en bloc resection of the thymoma, along with the thymic gland, perithymic fat tissue, mediastinal pleura ( $n=44 ; 57.9 \%)$, and pericardium $(n=33 ; 46.1 \%)$, was performed. When appropriate, the resection was extended to the lung $(n=32 ; 42.1 \%)$ or the diaphragm $(n=17 ; 22.4 \%)$. In patients with pleural tumor spread (Masaoka-Koga stage IVa: $n=28$ ), tumor resection was achieved by pleurectomy/decortication (P/D: $n=12$ ), extended P/D $(n=10)$, extrapleural pneumonectomy (EPP: $n=3)$, or localized pleural tumor resection $(n=3)$. An additional hyperthermic intrathoracic chemotherapy

Table 3 Operative and postoperative data

\begin{tabular}{ll}
\hline Variable & $n=76$ \\
& $(100 \%)$ \\
\hline Surgery & $41(53.9)$ \\
One approach & $35(46.1)$ \\
Two approaches & \\
Surgical procedure & $61(18.3)$ \\
Radical thymectomy & $12(15.8)$ \\
P/D & $10(13.2)$ \\
eP/D & $3(3.9)$ \\
EPP & $19(25)$ \\
HITHOC & \\
Completeness of resection & $37(48.7)$ \\
R0 & $28(36.8)$ \\
R1 & $11(14.5)$ \\
R2 & \\
Complications & $3(3.9)$ \\
Intraoperative & $10(13.2)$ \\
Postoperative & \\
Adjuvant treatment & $22(28.9)$ \\
Chemotherapy & $19(25)$ \\
Radiotherapy & $0(0)$ \\
30-day mortality & \\
\hline eP/D extended pleurectomy/decortication, EPP extrapleural pneumonectomy, \\
decortication, RO no residual tumor, R1 microscopic residual tumor, $R 2$ \\
macroscopic residual tumor
\end{tabular}


(HITHOC) with cisplatin was done in $n=19$ patients (68\%). A complete tumor resection (R0) was achieved in $48.7 \%$ of patients. A microscopic (R1: $n=28 ; 36.8 \%$ ) or macroscopic $(n=11 ; 14.5 \%)$ incomplete tumor resection was documented in advanced stages III $(n=12)$ and IV $(n=26)$, due to tumor infiltration of adjacent structures or diffuse pleural manifestation. Only one stage II tumor had a R1 situation, which was treated with adjuvant radiotherapy.

\section{Stage distribution}

Stage distribution according to the Masaoka-Koga staging system and the proposed TNM-staging system is based on the pathological results and shown in Table 4 . When comparing both classifications, Masaoka-Koga stage I patients $(n=9)$ increased to IASLC/ITMIG stage I patients $(n=23)$, and all Masaoka-Koga stage II patients $(n=14)$ decreased to $n=1$ IASLC/ITMIG stage II patient. One patient with infiltration of the pericardium (Masaoka-Koga stage III) is now classified as IASLC/ ITMIG stage II patient. The proportion of patients with advanced tumor stages III and IV was nearly similar between both classifications. The stage distribution of the new system in relation to the WHO classification is presented in Table 5. Advanced tumor stages are associated with higher levels of WHO stages (B2 to C).

\section{Survival analysis}

Overall 5-year survival rate of all patients was $73 \%$. Because of the small sample size if distributed in all stages, early stages I and II were joint together $(n=23)$ and compared to advanced stage III $(n=20)$ or stage IV $(n=33)$. Overall survival curves of the three subgroups according to both staging systems are displayed in Fig. 1. Within each staging system, the survival curves differed significantly. A better survival for stage IV (MasaokaKoga 77\%; IASLC/ITMIG 70\%) compared to stage III (Masaoka-Koga 49\%; IASLC/ITMIG 54\%) was observed. Overall 5-year recurrence-free survival was 66\% irrespective of stage. Early stages had a significant longer

Table 4 Patient distribution ( $n$ ) between proposed IASLC/ITMIG stages and Masaoka-Koga classification

\begin{tabular}{lllllllll}
\hline & & \multicolumn{1}{l}{ IASLC/ITMIG stages } & & Total \\
\cline { 3 - 7 } & & I & II & IIla & IIb & IVa & IVb & \\
\hline Masaoka-Koga & I & 9 & 0 & 0 & 0 & 0 & 0 & 9 \\
& IIa & 6 & 0 & 0 & 0 & 0 & 0 & 6 \\
& IIb & 8 & 0 & 0 & 0 & 0 & 0 & 8 \\
& III & 0 & 1 & 15 & 2 & 2 & 0 & 20 \\
& IVa & 0 & 0 & 0 & 0 & 28 & 0 & 28 \\
& IVb & 0 & 0 & 0 & 0 & 0 & 5 & 5 \\
\hline \multirow{5}{*}{ Total } & & 23 & 1 & 15 & 2 & 30 & 5 & 76 \\
\hline
\end{tabular}

Table 5 Patient distribution (n) between proposed IASLC/ITMIG stages and WHO classification

\begin{tabular}{|c|c|c|c|c|c|c|c|c|}
\hline & & \multicolumn{6}{|c|}{ IASLC/ITMIG stages } & \multirow[t]{2}{*}{ Total } \\
\hline & & I & $\|$ & IIIa & $\mathrm{IIlb}$ & $\mathrm{IVa}$ & $\mathrm{IVb}$ & \\
\hline \multirow[t]{7}{*}{$\mathrm{WHO}$} & $A$ & 2 & 0 & 0 & 0 & 0 & 0 & 2 \\
\hline & $A B$ & 4 & 0 & 0 & 0 & 1 & 0 & 5 \\
\hline & B1 & 2 & 0 & 1 & 0 & 2 & 0 & 5 \\
\hline & B2 & 9 & 1 & 6 & 0 & 10 & 2 & 28 \\
\hline & Mixed B2/B3 & 1 & 0 & 3 & 0 & 4 & 0 & 8 \\
\hline & B3 & 4 & 0 & 3 & 2 & 9 & 0 & 18 \\
\hline & C & 1 & 0 & 2 & 0 & 4 & 3 & 10 \\
\hline Total & & 23 & 1 & 15 & 2 & 30 & 5 & 76 \\
\hline
\end{tabular}

recurrence-free survival (Masaoka-Koga 90\%, $p=0.007$; IASLC/ITMIG $86 \%, p=0.019)$ than advanced stages III and IV (55 to $56 \%$ ), which were nearly similar (Fig. 2).

All patients with stage IVa tumors due to pleural spread received multimodality therapy and reached a 5year survival rate up to $79 \%$. No significant differences in survival were documented between primary and secondary (recurrence) stage IVa $(p=0.616)$.

The hazard ratios for all stages and subgroups for both staging systems using the Cox regression analysis are listed in Table 6. Overall survival in patients with Masaoka-Koga stage III $(p=0.02)$ or IASLC/ITMIG stage IIIa/IIIb $(p=0.03)$ was significantly declined. Multivariate analysis was performed including stage, resection status, and histology and showed that only the classification according to IASCL/ITMIG significantly ( $p=0.03)$ influenced the overall survival.

\section{Discussion}

The tumor-node-metastasis (TNM) classification of cancers proposed by the UICC is used worldwide and accepted as a uniform classification system. It provides a stage-adapted indication system for therapy and helps to estimate patients' prognosis [14]. Recently, there is a proposed TNM-staging system, which should be applicable to all types of thymic malignancies. This new system is based on a large collaborative amount of 10.808 patient data available from the ITMIG/IASLC retrospective database, leaving 8.145 of patients for final analysis. Surgery was included in $99 \%$ of these cases $[11,17]$.

In our study sample, the proportion of patients with the proposed IASLC/ITMIG stage I increased remarkably because they were reclassified from Masaoka-Koga stage IIa and IIb diseases. However, this changing in distribution of early-stage thymoma had no impact on indication for radical surgery.

The Masaoka-Koga stage III is heterogenous, because it includes invasion of the mediastinal pleura (T1b), pericardium (T2), and other surrounding structures (T3, T4) 

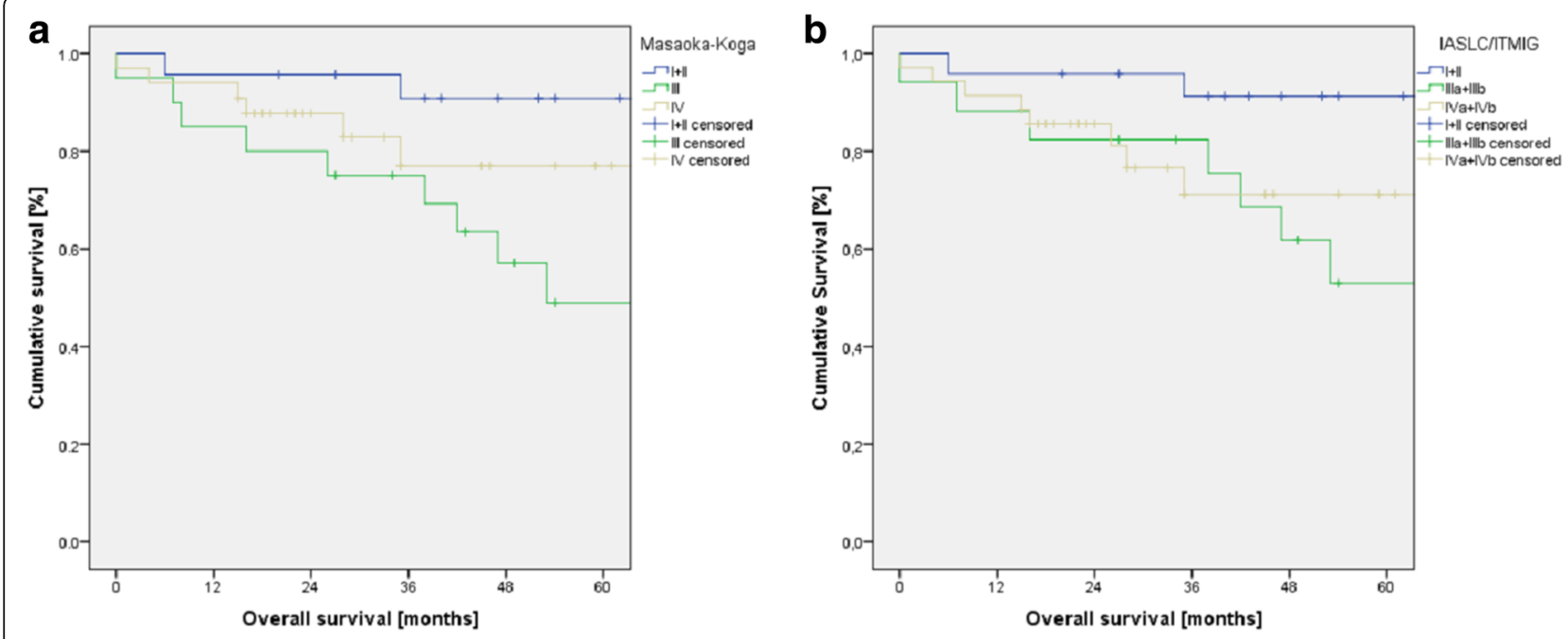

Fig. 1 The number of patients in each subgroup is presented as well as the 5-year survival rate [\%]. a Significant differences in survival were documented with respect to three groups of Masaoka-Koga stages. Stage III patients had a lower survival than patients with stage IV. b Survival curves with respect to the proposed IASLC/ITMIG stages showed also significant differences

[20]. In the new proposed system, stage III is divided in more or most resectable stage IIIa and less or unresectable stage IIIb tumors [17]. According to that, both patients with stage IIIb in this study had invasion of the aorta or the supraaortic branches and should be considered only individually for surgical resection, since the risk of $\mathrm{R} 2$ resection is high [21]. Therefore, the TNM system better characterizes this heterogenous stage III and supports the indication for surgery or not surgery. Nevertheless, worst survival was registered in patients with Masaoka-Koga stage III or proposed stage IIIa/IIIb thymic tumors.
Especially in patients with advanced thymoma not eligible for immediate resection, induction therapy is recommended [22]. Surgical resection should be part of a multimodality therapy including chemotherapy and in some cases adjuvant radiotherapy to decrease the risk of recurrence and improve survival [23, 24]. These neoadjuvant treatment indications were not influenced by the new TNM-staging system.

Furthermore, the new TNM-staging proposal also provides information on lymphatic involvement and tumor dissemination $[13,18]$. Since the significance of the lymph node dissection and its impact on adjuvant
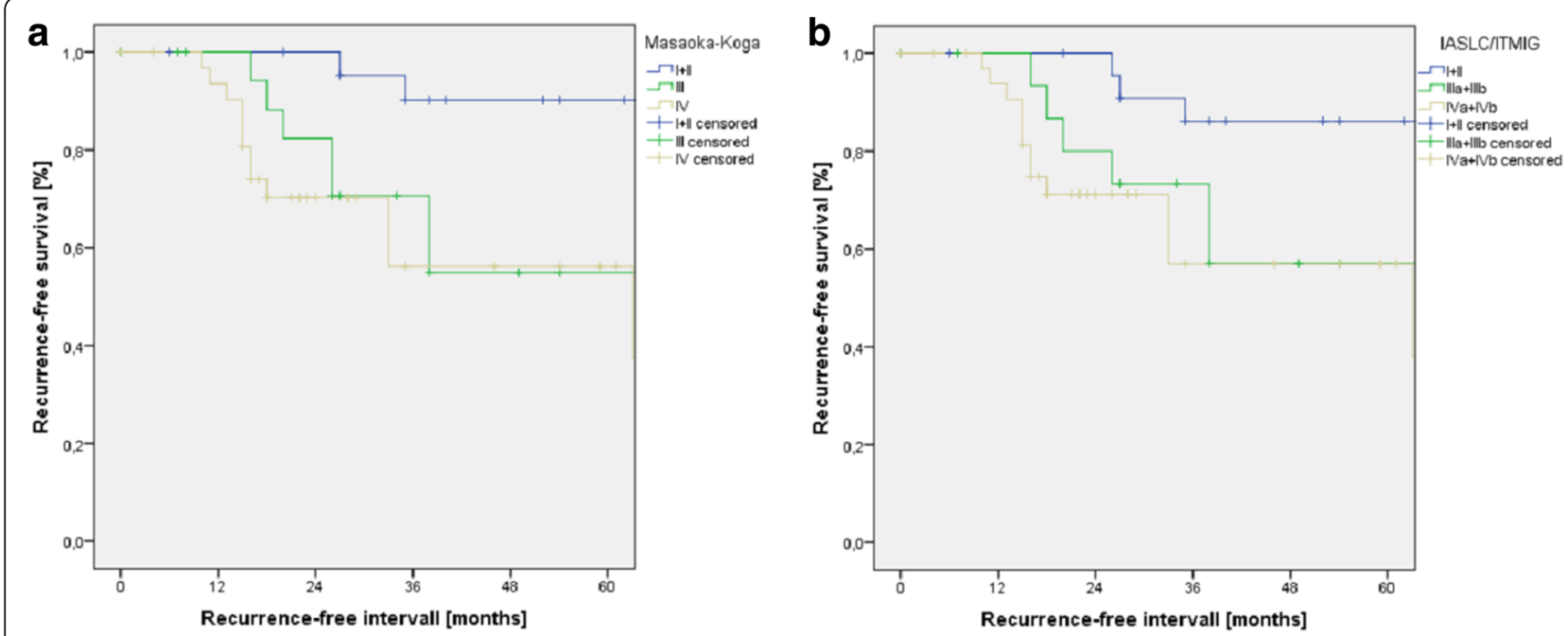

Fig. 2 Recurrence-free survival curves for patient subgroups according to the three stage groupings. There were significant differences between stage I + II compared to stage III or stage IV with respect to the Masaoka-Koga (a) and the proposed IASLC/ITMIG (b) staging system. Recurrencefree survival was nearly similar between stage III and stage IV 
Table 6 Comparison of hazard ratios between Masaoka-Koga and proposed IASLC/ITMIG stages using Cox's regression analysis

\begin{tabular}{|c|c|c|c|c|c|c|}
\hline & \multicolumn{3}{|c|}{ Overall survival } & \multicolumn{3}{|c|}{ Recurrence-free survival } \\
\hline & $H R$ & $95 \% \mathrm{Cl}$ & $p$ value & $H R$ & $95 \% \mathrm{Cl}$ & $p$ value \\
\hline \multicolumn{7}{|c|}{ Masaoka-Koga } \\
\hline $\mid+\|$ & 1.00 & & 0.054 & 1.00 & & 0.03 \\
\hline III & 6.38 & $1.38-29.59$ & 0.02 & 5.79 & $1.19-28.01$ & 0.03 \\
\hline $\mathrm{IVa}+\mathrm{IVb}$ & 3.64 & $0.75-17.67$ & 0.11 & 8.1 & $1.78-36.79$ & 0.007 \\
\hline \multicolumn{7}{|l|}{ IASLC/ITMIG } \\
\hline $\mid+\|$ & 1.00 & & 0.09 & 1.00 & & 0.04 \\
\hline\|\|$l a+\| l b$ & 5.71 & $1.19-27.49$ & 0.03 & 3.66 & $0.91-14.67$ & 0.07 \\
\hline $\mathrm{IVa}+\mathrm{IVb}$ & 4.73 & $1.01-22.1$ & 0.048 & 5.31 & $1.47-19.15$ & 0.01 \\
\hline
\end{tabular}

therapy are still not clear, the imperative for a radical lymph node dissection remains questionable $[16,25]$. So, most of all do not routinely perform a systematic lymph node dissection in all patients with thymoma and only suspicious nodes were resected for histological investigation. Therefore, we have problems with defining accurately the lymph node status [26].

The changing within early stages did not negatively affect the 5-year survival rate of $91 \%$, because both early stages I and II include tumors, which should be completely resectable, even if they show invasion of the perithymic fat tissue, the mediastinal pleura, or the pericardium. Less imbalance of stage distribution was found in advanced stages III and IV. These results are also in line with the literature [27].

Both, overall survival and recurrence-free survival were significantly influenced by the three stage groupings in early (I + II), advanced (III), and metastatic (IV) stages. In contrast, a recent study showed only a significant deterioration regarding the recurrence-free survival and not the overall survival [27]. Overall 5-year survival of $73 \%$ and recurrence-free survival of $66 \%$ for all patients in this study group was encouraging, although approximately $69 \%$ of patients had advanced stages III and IV thymoma/thymic carcinoma.

The survival curves in both staging systems showed a significant deterioration of prognosis as the stage increased up to stage III. In contrast, stage IV patients with pleural or lymphatic tumor spread had a significant better overall survival than patients in stage III. This survival benefit might be explained, because almost all our patients in Masaoka-Koga stage IVa underwent successful radical surgical resection, which was also combined with the HITHOC (68\%) within the last years [28]. Finally, surgical resection within a multimodality treatment concept in patients with pleural tumor dissemination is feasible and leads to encouraging 5-year survival rates up to $79 \%$. This multimodality treatment regime might not be performed in all patients of the collaborative IASLC/ITMIG database and therefore was not taken into account for the final analysis. In addition, advanced stages were probably underrepresented compared to earlier stage tumors [13].

The recurrence-free survival was nearly similar between stage III and IV tumors. That means the biological behavior (e.g., recurrence) of the tumor seems not to be influenced by the tumor stage. But the consequence of tumor recurrence seems to be different in both stages, since mediastinal recurrence after stage III tumors often directly involves vitally important structures (i.e., great vessels, heart). On the other hand, pleural recurrences usually do not affect vital organs and therefore can often be treated again surgically, which leads to a prolonged survival. These patients might benefit from multimodal treatment including surgery and should be evaluated interdisciplinary [3, 29-31].

\section{Conclusion}

In conclusion, the new TNM-staging system presents a clinically useful and applicable system, which can be used for indication and stage-adapted therapy. It also seems to serve as a potential prognostic prediction model for overall and recurrence-free survival. Advanced stage IVa patients can be treated with multimodality therapy including radical surgery, which results in a longer survival compared to patients with stage III. Systematic lymph node dissection is recommended and has a strong impact on stage distribution (stage IV). We all should perform systematic lymph node dissection, although its impact on adjuvant therapy and prognosis is still controversial. Further studies using prospectively collected data (especially advanced stages and lymph node status) of large patient cohorts on the proposed TNM-staging system are warranted to prove our results and would be helpful for uniform classification of thymic tumors, stage-adapted therapy, and prediction of prognosis.

\section{Strengths and limitations}

We are aware of the potential restrictions of our study. The obvious limitation is its retrospective, nonrandomized nature. All data were revalidated by another coauthor before analysis. This procedure should have reduced errors, but did not eliminate them completely. In particular, the sample size is limited. However, we present a cohort of surgical patients with a high percentage of advanced stages, who were treated within a multimodality therapy regime. We have a complete follow-up of all patients; thus, the follow-up period might be relatively short for thymoma, because of the slow progression and late recurrence of this tumor entity. 


\section{Acknowledgements}

Not applicable.

\section{Funding}

There was no funding

\section{Availability of data and materials}

The datasets generated and/or analyzed during the current study are not publicly available due to internal records of patient data and privacy policy but are available from the corresponding author on a reasonable request.

\section{Authors' contributions}

MR and MME made substantial contributions to the design of this study, acquisition of data, data analysis, and interpretation of data. MR wrote and revised the manuscript. RN, ZS, and HSH participated in the design of this study and have been involved in revising the manuscript critically for important intellectual content. All authors read and approved the final manuscript.

\section{Ethics approval and consent to participate}

The study was approved by our Institutional Review Board (University Hospital Regensburg), which waived the requirement for an individual patient consent because only routine patient data were used for this retrospective analysis.

\section{Consent for publication}

Not applicable.

\section{Competing interests}

The authors declare that they have no competing interests.

\section{Publisher's Note}

Springer Nature remains neutral with regard to jurisdictional claims in published maps and institutional affiliations.

\section{Author details}

'Department of Thoracic Surgery, University Medical Center Regensburg, Franz-Josef-Strauß-Allee 11, 93053 Regensburg, Germany. ${ }^{2}$ Department of Thoracic Surgery, Hospital Barmherzige Brüder Regensburg, Regensburg, Germany.

Received: 1 June 2017 Accepted: 23 November 2017

Published online: 02 December 2017

\section{References}

1. Detterbeck FC, Parson AM. Thymic tumors. Ann Thorac Surg. 2004;77:1860-9.

2. Venuta F, Anile M, Diso D, et al. Thymoma and thymic carcinoma. Eur J Cardiothoracic Surg. 2010;37:13-25.

3. Ried M, Marx A, Götz A, Hamer O, Schalke B, Hofmann HS. State of the art: diagnostic tools and innovative therapies for treatment of advanced thymoma and thymic carcinoma. Eur J Cardiothorac Surg. 2016:49(6):1545-52.

4. Masaoka A, Monden Y, Nakahara K, Tanioka T. Follow-up study of thymomas with special reference to their clinical stages. Cancer. 1981;48:2485-92.

5. Koga K, Matsuno Y, Noguchi M, et al. A review of 79 thymomas: modification of staging system and reappraisal of conventional division into invasive and non-invasive thymoma. Pathol Int. 1994;44(5):359-67.

6. Rosai J, Sobin L. Histological typing of tumours of the thymus. In: World Health Organization, editor. International histological classification of tumours. Heidelberg: Springer; 1999. p. 1-16

7. Detterbeck FC, Nicholson AG, Kondo K, Van Schil P, Moran C. The MasaokaKoga stage classification for thymic malignancies: clarification and definition of terms. J Thorac Oncol. 2011;6:1710-6.

8. Cardillo G, Carleo F, Giunti R, et al. Predictors of survival in patients with locally advanced thymoma and thymic carcinoma (Masaoka stages III and IVa). Eur J Cardiothoracic Surg. 2010;37:819-23.

9. Filosso PL, Ruffini E, Lausi PO, Lucchi M, Oliaro A, Detterbeck F. Historical perspectives: the evolution of the thymic epithelial tumors staging system. Lung Cancer. 2014;83:126-32.

10. Detterbeck F, Youssef $S$, Ruffini $E$, et al. A review of prognostic factors in thymic malignancies. J Thorac Oncol. 2011;6:S1698-704.
11. Detterbeck FC, Asamura H, Crowley J, et al. Staging and Prognostic Factors Committee; Members of the Advisory Boards; Participating Institutions of the Thymic Domain. The IASLC/ITMIG thymic malignancies staging project: development of a stage classification for thymic malignancies. J Thorac Oncol 2013; 8: 1467-1473.

12. Huang J, Ahmad U, Antonicelli A, et al. International Thymic Malignancy Interest Group International Database Committee and Contributors. Development of the international thymic malignancy interest group international database: an unprecedented resource for the study of a rare group of tumors. J Thorac Oncol 2014; 9: 1573-1578. Erratum in: J Thorac Oncol 2014; 9: 1804.

13. Detterbeck FC, Stratton K, Giroux D, et al. The IASLC/ITMIG thymic epithelial tumors staging project: proposal for an evidence-based stage classificationsystem for the forthcoming $\left(8^{\text {th }}\right)$ edition of the TNM classification of malignant tumors. J Thorac Oncol. 2014;9:65-72.

14. Brierley JD, Gospodarowicz MK, Wittekind C. TNM classification of malignant tumours. 8th ed. Hoboken: Wiley-Blackwell; 2016. ISBN: 978-1-119-26357-9

15. Marx A, Ströbel P, Badve SS, et al. ITMIG consensus statement on the use of the WHO histological classification of thymoma and thymic carcinoma: refined definitions, histological criteria, and reporting. J Thorac Oncol. 2014;9(5):596-611.

16. Huang J. A new staging system for thymoma-will it improve outcomes? J Thorac Cardiovasc Surg. 2016;151(1):20-2.

17. Nicholson AG, Detterbeck FC, Marino M, et al. Staging and prognostic factors committee; members of the advisory boards; participating institutions of the Thymic domain. The IASLC/ITMIG Thymic Epithelial Tumors Staging Project: proposals for the T component for the forthcoming (8th) edition of the TNM classification of malignant tumors. J Thorac Oncol 2014; 9 (9 Suppl 2): S73-S80

18. Bhora FY, Chen DJ, Detterbeck FC, et al. Staging and prognostic factors committee; advisory boards. The ITMIG/IASLC Thymic Epithelial Tumors Staging Project: a proposed lymph node map for thymic epithelial tumors in the forthcoming 8th edition of the TNM classification of malignant tumors. J Thorac Oncol 2014; 9 (9 Suppl 2): S88-S96.

19. Kondo K, Van Schil P, Detterbeck FC, et al. Staging and Prognostic Factors Committee; Members of the Advisory Boards; Participating Institutions of the Thymic Domain. The IASLC/ITMIG Thymic Epithelial Tumors Staging Project: proposals for the N and M components for the forthcoming (8th) edition of the TNM classification of malignant tumors. J Thorac Oncol 2014; 9 (9 Suppl 2): S81-S87.

20. Liang G, Gu Z, Li Y, et al. Members of the Chinese alliance for research in Thymomas. Comparison of the Masaoka-Koga staging and the International Association for the Study of Lung Cancer/the International Thymic Malignancies Interest Group proposal for the TNM staging systems based on the Chinese Alliance for Research in Thymomas retrospective database. J Thorac Dis. 2016;8(4):727-37.

21. Ried M, Neu R, Schalke B, von Süßkind-Schwendi M, Sziklavari Z, Hofmann $H S$. Radical surgical resection of advanced thymoma and thymic carcinoma infiltrating the heart or great vessels with cardiopulmonary bypass support. J Cardiothorac Surg. 2015;10(1):137.

22. Spaggiari L, Casiraghi M, Guarize J. Multidisciplinary treatment of malignant thymoma. Curr Opin Oncol. 2012;24:117-22.

23. Lucchi M, Ambrogi MC, Duranti $L$, et al. Advanced stage thymomas and thymic carcinomas: results of multimodality treatments. Ann Thorac Surg. 2005;79(6):1840-484

24. Rajan A, Giaccone G. Treatment of advanced thymoma and thymic carcinoma. Curr Treatment Options Oncol. 2008;9:277-87.

25. Hwang Y, Park IK, Park S, Kim ER, Kang CH, Kim YT. Lymph node dissection in thymic malignancies: implication of the ITMIG lymph node map, TNM stage classification, and recommendations. J Thorac Oncol. 2016;11 (1):108-14.

26. Viti A, Bertolaccini L, Terzi A. What is the role of lymph nodal metastases and lymphadenectomy in the surgical treatment and prognosis of thymic carcinomas and carcinoids? Interact Cardiovasc Thorac Surg. 2014;19(6):1054-8.

27. Fukui T, Fukumoto K, Okasaka T, et al. Clinical evaluation of a new tumournode-metastasis staging system for thymic malignancies proposed by the International Association for the Study of Lung Cancer Staging and Prognostic Factors Committee and the International Thymic Malignancy Interest Group. Eur J Cardiothorac Surg. 2016;49(2):574-9.

28. Ried M, Potzger T, Braune N, et al. Cytoreductive surgery and hyperthermic intrathoracic chemotherapy perfusion for malignant pleural tumors: perioperative management and clinical experience. Eur J Cardiothorac Surg. 2013;43(4):801-7. 
29. Marulli G, Lucchi M, Margaritora S, et al. Surgical treatment of stage III thymic tumors: a multi-institutional review from four Italian centers. Eur J Cardiothorac Surg. 2011;39(3):1-7.

30. Ruffini E, Detterbeck F, Van Raemdonck D, et al. Thymic carcinoma: a cohort study of patients from the European society of thoracic surgeons database. J Thorac Oncol. 2014;9(4):541-8.

31. Rimner A, Yao X, Huang J, et al. Postoperative radiation therapy is associated with longer overall sunvival in completely resected stage II and III thymoma-an analysis of the International Thymic Malignancies Interest Group (ITMIG) retrospective database. J Thorac Oncol. 2016;23 Epub ahead of print

Submit your next manuscript to BioMed Central and we will help you at every step:

- We accept pre-submission inquiries

- Our selector tool helps you to find the most relevant journal

- We provide round the clock customer support

- Convenient online submission

- Thorough peer review

- Inclusion in PubMed and all major indexing services

- Maximum visibility for your research

Submit your manuscript at www.biomedcentral.com/submit
Biomed Central 